\title{
Calorie restriction with regular chow, but not a high-fat diet, delays onset of spontaneous osteoarthritis in the Hartley guinea pig model
}

\author{
Lauren B. Radakovich ${ }^{1}$, Angela J. Marolf², Lauren A. Culver ${ }^{1}$ and Kelly S. Santangelo ${ }^{1 *}$ (D)
}

\begin{abstract}
Background: Obesity is a leading risk factor for osteoarthritis (OA). In contrast, calorie restriction (CR) may lessen OA due to improved systemic inflammatory status and reduced weight-bearing. The aim of this study was to determine how CR with regular chow versus a high-fat diet (HFD) alters OA progression using the Hartley guinea pig model of disease.

Methods: Twenty-four male guinea pigs were allocated to four groups at 2 months of age: (1) ad libitum regular chow (obese), (2) CR regular chow (lean), (3) ad libitum HFD, and (4) CR HFD. Animals in both HFD groups ate identical amounts and were combined into one HFD group for analyses. At 5 months, hind limbs were harvested for microcomputed tomography (microCT) and histopathologic evaluation of knee OA. Total body, gonad fat, and infrapatellar fat pad (IFP) masses were recorded. IFPs were collected for gene expression analysis. Immunohistochemistry for monocyte chemoattractant protein-1 (MCP-1) was performed on intact joints. Serum was utilized for protein C3 measurement. All data were compared using ordinary one-way ANOVA analyses with Tukey's post-hoc tests.

Results: Body mass in the lean and HFD groups were similar and lower than the obese group. Despite this, gonad fat pads in the HFD group were comparable to the obese group. MicroCT and histologic OA scores were similar in obese and HFD groups; both scores were significantly lower in the lean group. Obese and HFD groups displayed increased gene expression of pro-inflammatory and catabolic mediators in IFPs relative to lean animals. Consistent with this, immunohistochemistry for MCP-1 in knee joints demonstrated strong positive staining in obese and HFD groups but was minimally detected in lean animals. Serum protein C3 levels were also statistically higher.

Conclusions: This study demonstrated that CR with a regular chow diet lessened knee OA in the Hartley guinea pig and was associated with decreased local and systemic inflammation compared to obese animals. HFD animals, although under CR conditions, had OA scores and inflammatory markers similar to obese animals. Thus, diet composition, and not solely body weight, may be a key factor in development of OA.
\end{abstract}

Keywords: Osteoarthritis, High-fat diet, Obesity, Calorie restriction, Hartley guinea pig

\footnotetext{
*Correspondence: Kelly.Santangelo@colostate.edu

'Department of Microbiology, Immunology, Pathology, Colorado State

University, 200 West Lake Street, Fort Collins, CO 80521, USA

Full list of author information is available at the end of the article
}

(c) The Author(s). 2019 Open Access This article is distributed under the terms of the Creative Commons Attribution 4.0 International License (http://creativecommons.org/licenses/by/4.0/), which permits unrestricted use, distribution, and reproduction in any medium, provided you give appropriate credit to the original author(s) and the source, provide a link to the Creative Commons license, and indicate if changes were made. The Creative Commons Public Domain Dedication waiver (http://creativecommons.org/publicdomain/zero/1.0/) applies to the data made available in this article, unless otherwise stated. 


\section{Background}

Osteoarthritis (OA), particularly knee OA, is a debilitating degenerative disorder affecting many people worldwide [1]. While OA secondary to a joint injury is typically associated with a defined onset, naturally occurring OA occurs in the absence of specific trauma for reasons that are not yet understood. Advancing age has long been the primary risk factor for development of spontaneous OA [2]; however, obesity is encroaching on age as a leading OA hazard given the alarming rise in obesity rates across the globe $[3$, 4]. The relationship between $O A$ and obesity has been an area of increasing interest to researchers, but the mechanisms connecting these two conditions remain loosely defined. Early studies suggested that increased mechanical loading on joints contributed to worsened $\mathrm{OA}$ in obese patients [5]. However, higher incidence of OA in nonweight-bearing joints, such as in the hands [6], indicates that increased joint load may not be the only factor at play. Thus, dietary factors, including food composition and total calorie intake, likely play a complex role in the development of primary OA.

Recent studies have placed emphasis on the role systemic metabolic disturbances may play in the development of OA [5, 7-10]. Obesity is often associated with chronic, lowgrade systemic inflammation [11-14]. For example, as the volume of adipose tissue expands, it outgrows its blood supply, leading to tissue hypoxia and stimulation of proinflammatory cytokines [15]. Enhanced lipopolysaccharide translocation from the gut to the bloodstream is another contributor to a chronic inflammatory state in obese individuals, particularly in response to high dietary fat content [16]. Similarly, high levels of circulating saturated fatty acids stimulate innate immune receptors such as toll-like receptor 4, resulting in a heightened pro-inflammatory state [15]. Increased circulating leptin concentration in obese individuals can also promote inflammation via stimulation of cytokines such as interleukin (IL)-1 beta (IL-1 $\beta$ ), tumor necrosis factor (TNF), and IL-6 [17]. Additionally, high leptin levels have been shown to promote OA via increased activity of cartilage-degrading matrix metalloproteinases (MMPs) and aggrecanases [15, 18].

Previous work examining the role of obesity in promoting OA has concentrated on utilizing high-fat diets (HFDs) in mouse [19-23], rat [16, 24], and, less often, rabbit [25] animal models. Many of these studies have focused on post-traumatic OA secondary to surgical injury with a lesser number centered on naturally-occurring OA. Collectively, these studies provide convincing evidence that high-fat diet-induced obesity leads to worsened OA severity. Many have demonstrated that it is the increased fat mass, not overall body weight, associated with high-fat diets that is correlated with OA severity $[16,19,20,22,25]$. This is likely attributed to the metabolically active, inflammatory cytokine-producing nature of this adipose tissue. Diets used in these rodent studies vary in the amount of fat present, although $40-60 \%$ fat (derived from animal-based saturated fats) is typical. While such a high percentage of fat is effective in inducing obesity in mice and rats, it does not accurately reflect human diets, which are closer to $30 \%$ fat in a standard Western diet [26].

While HFDs have a detrimental effect on health, calorie restriction has emerged as a lifestyle factor that can prolong life and decrease the likelihood of developing chronic diseases such as atherosclerosis, type II diabetes, and neurodegenerative disease [27]. These positive effects are due to decreased oxidant damage, increased DNA repair, and decreased production of inflammatory cytokines secondary to less adipose tissue mass [28-31]. Few studies, however, have examined the effects of calorie restriction on development of OA. In dogs, calorie restriction appeared to delay onset of OA [32, 33]. A long-term study in mice did not show any differences in histologic OA severity between ad libitum and calorierestricted mice, although it should be noted that fat mass was not different between the groups at the end of the study [27]. There is also one study examining calorie restriction in the Hartley guinea pig model of spontaneous OA. This work demonstrated that calorie restriction resulted in lessened OA severity at both 9 and 18 months of age [34], time points that correspond to lateand end-stage disease, respectively. Given this, we were interested in pursuing the influence of calorie restriction at earlier ages in the time course of disease.

Guinea pigs are perhaps an underutilized rodent model of OA. In particular, the Hartley strain is a useful model of spontaneous knee joint OA, as it develops disease in a condensed time frame and demonstrates bilateral pathologic lesions that are nearly identical to those seen in humans with aging-related OA [35, 36]. Guinea pigs have also emerged as being suitable models for a variety of metabolic diseases, including cardiovascular disease, atherosclerosis, and type II diabetes [37-39]. Furthermore, guinea pig lipid metabolism is more comparable to human lipid metabolism than any other rodent [37, 40-42]. High-fat diets have been successfully used in guinea pigs to drive metabolic diseases, such as type II diabetes [37] and non-alcoholic fatty liver disease [43]. In contrast to mouse and rat studies using a highfat diet, the diets used in these guinea pig studies tend to range from 20 to $30 \%$ fat, which is more typical of a Westernized human diet. High-fat diets used in guinea pig studies also have a mixture of saturated animalbased fats and unsaturated plant-based fats. As guinea pigs are more fastidious about diet than mice and rats, they do not tend to develop overt obesity in concert with metabolic derangements when fed high-fat diets [37, 43]. This may allow for evaluation of the metabolic effects of HFDs without the potential confounding influence of 
mechanical factors associated with overt obesity. To date, there are no studies exploring the potential role that a high-fat diet may play in the development of spontaneous $\mathrm{OA}$ in a guinea pig model.

Collectively, the aims of the current study were to compare and contrast the effects of overconsumption and calorie restriction using standard rodent chow to that of a HFD on the onset of spontaneous OA in a guinea pig model. We hypothesized that animals on a HFD would exhibit worsened OA scores compared to both ad libitum and calorie-restricted animals on a regular chow diet. Likewise, we expected calorie restriction to result in improved OA scores at this early time point.

\section{Methods}

\section{Animals}

All procedures were approved by the university's Institutional Animal Care and Use Committee and were performed in accordance with the NIH Guide for the Care and Use of Laboratory Animals. Twenty-four 6- to 7week-old male Dunkin-Hartley guinea pigs were purchased from a commercial vendor (Charles River Laboratories, Wilmington, MA). Animals were maintained at Colorado State University's Laboratory Animal Resources housing facilities and were monitored daily by a veterinarian. All guinea pigs were singly-housed in solid bottom cages and provided ad libitum access to water daily.

After 1 week of acclimation, animals were randomly allocated to one of four feeding groups: (1) ad libitum regular chow (obese), (2) calorie-restricted regular chow (lean), (3) ad libitum HFD, and (4) calorie-restricted HFD. As laboratory-raised guinea pigs fed ad libitum often become obese with age [44], this first group was referred to as such in the current study. Further, as animals in group 3 were noted to self-restrict consumption of the HFD to the same amount as those in group 4 ( $25 \mathrm{~g})$, this group was condensed to a single HFD group. All animals were harvested at 5 months of age, a time when this strain of guinea pig has recognized signs of early OA [35].

\section{Diet composition}

The regular chow diet (Teklad Global Guinea Pig Diet \#2040, Madison, WI) provided 31\% calories from protein, $12 \%$ from fat, and $57 \%$ from carbohydrate. This diet was supplemented with vitamin $C(1050 \mathrm{mg} / \mathrm{kg})$. Fat was derived from linseed meal. Protein and carbohydrates were derived from a mixture of alfalfa, wheat, oats, and fish meal. Animals fed ad libitum ate between 50 and 60 $\mathrm{g}$ of chow daily. Animals on the restricted regular chow diet received $30 \mathrm{~g}$ of food daily for the duration of the study [27]. The HFD (\#151006, Dyets Inc., Bethlehem, PA) provided $18 \%$ calories from protein, $30 \%$ from fat, and 52\% from carbohydrates. Fat was sourced from a mixture of Primex vegetable shortening and beef tallow.
The source of protein was isolated soy protein, and carbohydrates were derived from sucrose and fructose. All animals receiving the HFD consumed $25 \mathrm{~g}$ of food each day, which matched the calorie consumption of the restricted regular chow group.

\section{Tissue collection}

At the time of harvest, animals were anesthetized with a mixture of isoflurane and oxygen. Body weights were recorded at this time. Thoracic cavities were opened, and blood was collected with 20-gauge butterfly catheter via direct cardiac puncture. After blood collection, anesthetized animals were immediately transferred to a carbon dioxide chamber for euthanasia. Hind limbs were removed at the coxofemoral joint. The left limb was placed into $10 \%$ neutral buffered formalin for $48 \mathrm{~h}$ and then transferred to PBS for microCT analysis. After microCT imaging was complete, tibial length was measured using calipers. Limbs were then transferred to a $12.5 \%$ solution of ethylenediaminetetraacetic acid (EDTA) at $\mathrm{pH} 7$ for decalcification. EDTA was replaced twice weekly for 6 weeks.

After the right hind limb was removed, the knee joint was exposed by dissecting through the quadriceps muscles and reflecting the patella distally. The infrapatellar fat pad (IFP) was removed from the patellar tendon, weighed, and then placed in All Protect Tissue Reagent (Qiagen) for gene expression analysis. Fat from the left epididymis (hence forth referred to as gonad fat) was removed and weighed. A section of masseter muscle was collected from each animal, and its width was measured.

\section{MicroCT}

Knee joints were scanned using the Inveon microPET/CT system (Siemens Medical Solutions, Malvern PA), with a voxel size of $18 \mu \mathrm{m}$, a voltage of $100 \mathrm{kV}$, and an exposure time of $2356 \mathrm{~ms}$. Clinical features of OA were scored on reconstructed microCT images using a whole-joint grading scheme developed by our lab in conjunction with a veterinary radiologist [45]. Features graded include presence/size and location of osteophytes, subchondral bone cystic changes, subchondral bone sclerosis, articular bone lysis, and intraarticular soft tissue mineralization. Images were scored in duplicate in a random order, blinded to diet group. An intraclass correlation coefficient of 1.0 for intra-reviewer consistency was calculated.

\section{Histologic grading of $O A$}

After decalcification, coronal slices of the knees at the level of the medial tibial plateau were sectioned, as previously described [35]. Samples were paraffin embedded and a $5-\mu \mathrm{m}$ intact central section was stained with toluidine blue. Medial and lateral femoral condyles, along with medial and lateral tibial plateaus, were scored using the recommended published guidelines [35]. This 
semiquantitative histopathologic grading scheme is based on articular cartilage structure, proteoglycan content, cellularity, tidemark integrity, and presence of osteophytes. Scores were performed in a blinded fashion by two independent pathologists (LBR and KSS). Scores from each of the four anatomic locations were summed to obtain a total knee joint OA score for each guinea pig. An intraclass correlation coefficient of 0.9 for between reviewer consistency was calculated.

\section{Immunohistochemistry for MCP-1 on knee joints}

Immunohistochemistry (IHC) was performed on sections of knee joints using a polyclonal rabbit antibody to monocyte chemoattractant protein-1 (MCP-1) (Abcam ab9669) at a dilution of 1:100. Prior to incubation with primary antibody, slides were incubated in citrate buffer overnight at $55{ }^{\circ} \mathrm{C}$ for antigen retrieval, as recommended for skeletal tissues [46]. Slides were incubated in primary antibody overnight at $4{ }^{\circ} \mathrm{C}$, followed by a 30 -min incubation with a biotinylated goat anti-rabbit secondary antibody. Bone marrow hematopoietic cells and macrophages frequently exhibited MCP-1 staining, serving as internal positive controls for each section. Exposure to secondary antibody, alone, or rabbit immunoglobulin at a concentration matching that of the primary antibody did not result in any positive immunostaining. Sections were counterstained with hematoxylin, coverslipped, and viewed by light microscopy. At least four sections from each joint were examined for immunostaining in chondrocytes and associated matrix. The mean percentage of positive cells and mean integrated intensity (calculated as pixel area times mean intensity) were determined in articular cartilage (superficial, middle, and deep zones) from both femoral condyles and tibial plateaus using Image-Pro ${ }^{\circ}$ (Media Cybernetics, Rockville, MD). All calculations were performed using identical thresholds across all photographs.

\section{Complete blood count, serum biochemical profile and serum protein C3 measurement}

At the time of harvest, blood collected via cardiac puncture was allocated to $0.5 \mathrm{~mL}$ EDTA microtubes for complete blood count $(\mathrm{CBC})$. CBCs were performed at the CSU Clinical Pathology Laboratory using the Advia 120 hematology analyzer (Siemens, Munich, Germany) with instrument settings and software specifically designed for guinea pig samples. Blood films were manually reviewed, and a leukocyte differential count was performed by a veterinary clinical pathologist (LR). Remaining blood taken at euthanasia was placed in red top glass tubes to incite clotting. After $30 \mathrm{~min}$, red top tubes were adequately clotted and placed into a centrifuge at $5000 \times g$ for $10 \mathrm{~min}$ for serum collection. One aliquot of serum was submitted to the Colorado State University Clinical Pathology Laboratory for serum biochemical analysis using the Roche Cobas
6000 (Basel, Switzerland). Remaining serum was aliquoted to cryovials, snap frozen in liquid nitrogen, and then stored at $-80{ }^{\circ} \mathrm{C}$ for $\mathrm{C} 3$ analysis. Serum protein C3 levels were measured on snap frozen serum using a guinea pig-specific ELISA (Abcam ab157705) according to the manufacturer's protocol.

\section{Gene expression of IFP and gonad fat using NanoString technology}

Total RNA was extracted from IFP and gonad fat samples using an RNeasy Lipid Tissue Mini Kit (Qiagen, Hilden, Germany). RNA was quantified spectrophotometrically with a NanoDrop 2000 (ThermoFisher Scientific, Waltham, MA). A total of 250 ng of RNA, at a concentration of $20 \mathrm{ng} / \mu \mathrm{l}$, was sent to the University of Arizona Genetics Core for analysis. Custom, guinea pig-specific probes were designed and synthesized by NanoString Technologies (see Table 1 for genes analyzed). Data analysis was performed using nSolver ${ }^{\mathrm{Tw}}$ software provided by NanoString Technologies. Results, reported as absolute transcript counts, were normalized to positive controls and housekeeping genes. Data for the IFP is provided in the manuscript proper. Additional file 1: Table S1 provides gene expression data for gonad fat among the groups; Additional file 2: Table S2 compares gene expression data for IFP versus gonad fat within the three groups.

\section{Statistical analyses}

Group size and power were prospectively determined using the statistical software at www.stat.uiowa.edu/ rlenth/Power. Based on preliminary work, histologic assessment of OA was selected as the principle outcome. Utilizing a within-group error of 0.5 and a detectable contrast of 1.0 in a linear regression model, power associated with a Tukey/HSD post-test $($ alpha $=0.05)$ was calculated as 0.9 with a sample size of 6 per experimental group.

Data for total body weights, tibial length, gonad fat weight, IFP weight, masseter muscle width, histologic OA scores, clinical microCT OA scores, $\mathrm{CBC}$ values, serum biochemical values, serum protein $\mathrm{C} 3$ values, and NanoString mRNA normalized absolute counts were subjected to, and passed, normality testing via the Kolmogorov-Smirnov test. Data were compared using parametric ordinary one-way ANOVA analyses followed by Tukey's multiple comparisons tests to allow for adjusted $P$ values. Statistical significance was set at $P<$ 0.05. All statistical analyses were performed with GraphPad Prism (La Jolla, CA, USA).

\section{Results}

General description of guinea pigs in each diet group

All animals in each group survived the duration of the study. Final body weights for the obese group were significantly higher than both the lean and HFD groups. 
Table 1 Normalized absolute nCounter mRNA counts present in the IFP. Data is represented as the mean (range)

\begin{tabular}{|c|c|c|c|c|c|}
\hline Gene & Function & Obese & Lean & HFD & $P$ value \\
\hline IFNY & Pro-inflammatory cytokine & $7.222(4.360-11.440)$ & $15.64(7.060-20.44)$ & $16.31(2.490-37.06)$ & 0.1204 \\
\hline IL-10 & Anti-inflammatory cytokine & $11.95(9.680-14.87)$ & $8.283(2.350-13.74)$ & $13.94(3.660-23.90)$ & 0.1372 \\
\hline $\mid L-1 \beta$ & Pro-inflammatory cytokine & $30.41(15.75-71.81)$ & $29.45(24.01-39.37)$ & $42.97(22.21-53.90)$ & 0.0944 \\
\hline IL-4 & Th2 response, tissue repair/fibrosis & $15.54(13.73-20.83)$ & $13.60(7.060-17.58)$ & $22.63(13.13-37.33)$ & $0.0112^{*}$ \\
\hline IL-5 & $\begin{array}{l}\text { Promotes Ig production and } \\
\text { eosinophil activation }\end{array}$ & $18.13(12.91-22.65)$ & $13.12(9.750-18.09)$ & $25.97(16.04-41.05)$ & $0.0029^{*}$ \\
\hline IL-6 & Pro-inflammatory cytokine & $25.01(20.12-29.16)$ & $29.60(18.68-45.15)$ & $58.82(21.73-76.84)$ & $0.0151^{+}$ \\
\hline LIF & Anti-inflammatory cytokine & $23.78(18.37-32.85)$ & $28.21(16.52-38.43)$ & $28.71(12.02-42.72)$ & 0.5087 \\
\hline MCP-1 & Pro-inflammatory cytokine & $333.3(265.4-487.0)$ & $439.4(361.0-510.5)$ & $564.9(398.7-812.7)$ & $0.0005^{+}$ \\
\hline NFKB & $\begin{array}{l}\text { Pro-inflammatory transcription } \\
\text { factor }\end{array}$ & $112.1(95.20-132.7)$ & $119.7(102.8-145.1)$ & $161.0(107.8-231.4)$ & $0.0015^{*,+}$ \\
\hline $\operatorname{cox} 2$ & Pro-inflammatory enzyme & $32.61(23.52-54.11)$ & 34.99 (29.61-48.63) & $52.55(35.37-69.86)$ & $0.0010^{*},+$ \\
\hline Tacr1 & $\begin{array}{l}\text { Binds Substance } P \text {, pro-inflammatory, } \\
\text { causes pain }\end{array}$ & $205.3(142.0-276.1)$ & $167.8(121.6-254.9)$ & $211.3(107.4-340.4)$ & 0.3172 \\
\hline TGF- $\beta 1$ & $\begin{array}{l}\text { Tissue repair, both pro and } \\
\text { anti-inflammatory }\end{array}$ & $275.2(195.1-403.5)$ & $254.9(206.1-330.4)$ & $375.3(210.6-591.1)$ & $0.0173^{*}$ \\
\hline TNF & Pro-inflammatory cytokine & $10.92(8.710-13.53)$ & $8.082(7.060-9.000)$ & $15.07(7.290-22.49)$ & $0.0009^{*,+}$ \\
\hline HIF1a & Responds to hypoxia & $1640(1116-2020)$ & $1552(893.8-2654)$ & $1899(1170-3089)$ & 0.4487 \\
\hline MMP13 & Cleaves type II collagen & $19.74(13.12-31.65)$ & $11.88(8.790-14.26)$ & $35.43(15.31-59.03)$ & $0.0059^{*,+}$ \\
\hline MMP2 & Cleaves type IV collagen & $8192(6133-10,346)$ & $9722(7571-12,566)$ & $11,514(8944-14,686)$ & $0.0157^{+}$ \\
\hline MMP9 & $\begin{array}{l}\text { Cleaves type IV and V collagen, } \\
\text { activates neutrophils }\end{array}$ & $14.46(2.610-46.53)$ & $17.47(8.250-23.08)$ & $26.23(2.250-64.05)$ & 0.2951 \\
\hline Timp1 & Inhibits MMPs & 1310 (956.1-1709) & $1076(768.8-1563)$ & 1145 (761.4-1826) & 0.4103 \\
\hline Timp2 & Inhibits MMPs & $6270(4494-7529)$ & $7654(6354-9109)$ & $8014(6089-10,405)$ & $0.0248^{+}$ \\
\hline Adiponectin & Glucose sensitivity and FA oxidation & $10,530(8885-11,904)$ & $20,830(12666-24,246)$ & $23,818(9818-38,769)$ & $0.0093^{+}$ \\
\hline Leptin & $\begin{array}{l}\text { Inhibits hunger, resistance seen in } \\
\text { obesity }\end{array}$ & $6379(3975-9012)$ & $2296(1191-3651)$ & $9471(3921-26,498)$ & $0.0348^{*}$ \\
\hline LPL & Hydrolyzes TGs into FAs and glycerol & $2843(1188-3988)$ & $16,118(7900-22,842)$ & $7536(3271-16,678)$ & $<0.0001^{*,+,+}$ \\
\hline PPARY & $\begin{array}{l}\text { Lipid uptake and adipogenesis, } \\
\text { insulin sensitization, anti-inflammatory }\end{array}$ & $185.4(105.7-249.1)$ & $466.2(275.3-736)$ & $254.6(139.2-426.2)$ & $0.001^{*,+}$ \\
\hline
\end{tabular}

*difference between HFD and lean groups; + difference between HFD and obese groups; + difference between obese and lean groups

There was no difference in body weights between the lean and HFD groups (Fig. 1a). To ensure that differences in body weight were not attributable to variations in skeletal properties, tibial lengths from all animals were measured. There was no statistical difference in tibial length between any of the three diet groups (Fig. 1b). To determine if muscle mass may be different between the three groups, the width of the masseter muscle was measured and compared. Muscle width was significantly smaller in HFD group compared to the obese ad libitum regular chow group. Mean muscle width in the obese group was 5.8 $\mathrm{mm}(95 \%$ CI $4.4-7.2), 4.7 \mathrm{~mm}(95 \%$ CI $3.8-5.5)$ in the lean calorie-restricted group, and $3.6 \mathrm{~mm}$ (95\% CI 3.1$4.1)$ in the HFD group $(P=0.0029)$.

In addition to body weights, two adipose depots were also weighed and contrasted among the groups. Gonad fat (collected from the epididymis) was chosen to represent an abdominal adipose store, while the IFP was selected to represent a depot local to the knee joint. Despite differences in total body weights, gonad fat weights in the obese and HFD groups were similar. Gonad fat weight in both of these groups was significantly higher than that of the lean group (Fig. 2a). Interestingly, this pattern was not seen for IFP weight. IFP weights for all three groups were similar, with no statistical differences found (Fig. 2b).

\section{MicroCT and histologic assessment of $\mathrm{OA}$}

Osteoarthritis was assessed via two methodologies. MicroCT was utilized to examine bony changes associated with OA, while histologic assessment of joints via the OARSI grading scheme was used to evaluate articular cartilage abnormalities. Using the clinical OA microCT scoring system, both obese and HFD groups had similar OA scores. Scores for these groups were statistically higher than those reported in the lean group (Fig. 3). Of note, in the lean group, many of the animals had no microCT 


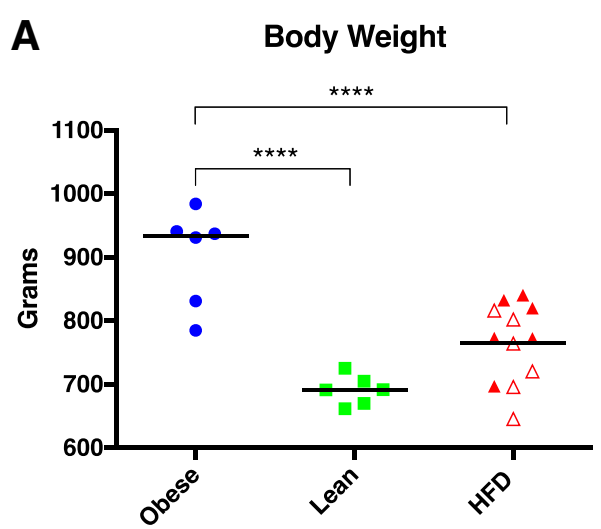

B

Tibial Length

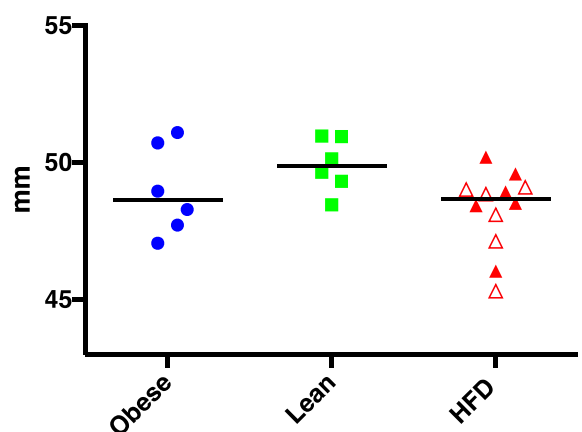

Fig. 1 Total body weight (a) and tibial length (b) in obese, lean, and HFD groups. Black line represents mean value. Open red triangles designate animals receiving the restricted HFD; closed triangles define animals on the ad libitum HFD. ${ }^{* * *} P<0.0001$

evidence of $\mathrm{OA}$ at 5 months of age, a time when early bony changes are consistently present in Hartley guinea pigs [35]. All animals in both the obese and HFD group had visible small enthesiophytes and/or osteophytes present on the patella and/or the tibia (Fig. 4). Subcondral bone sclerosis was also seen on the cranial patella. In contrast, only one animal in the lean group had a small osteophyte present on the patella. All remaining lean animals were radiographically normal, with no bony changes associated with OA.

The OARSI grading scheme resulted in a similar trend to that seen with the clinical microCT score. Again, both obese and HFD groups had similar OARSI OA scores that were significantly higher than those present in the lean group. Interestingly, although the total OA scores were similar in the obese and HFD groups, specific cartilage lesions appeared to differ. Articular cartilage surface fibrillation and superficial fissures were noted within the obese group (Fig. 5b, c). Superficial proteoglycan loss, with both focal and diffuse distributions, occasional chondrocyte clustering, and focal cell loss were noted in the HFD group (Fig. 5d-f). In the lean group, some animals exhibited mild superficial proteoglycan loss, but articular surface integrity was often maintained (Fig. 5a).

\section{$\mathrm{CBC}$, serum biochemistry, and protein $\mathrm{C} 3$ data}

Complete blood count, serum biochemistry data, and serum protein $\mathrm{C} 3$ were assessed for evidence of systemic inflammation and other metabolic effects the diet conditions had on normal physiology. On $\mathrm{CBC}$, platelet counts, which have been associated with increased levels of IL-6 in guinea pigs [47], were higher in the HFD group compared to both the lean and obese group. Additionally, platelet counts in the obese group were higher than those of the lean group, but not as high as the HFD group (Fig. 6a).

While increased platelet count can indicate a higher level of inflammation [48], it is non-specific and other indicators of inflammation, such as an increased white blood cell count, were not noted in this study. To more conclusively determine if a higher level of inflammation was present in the obese and HFD groups, a guinea pig-specific ELISA for protein $\mathrm{C} 3$, an acute phase reactant, was used to analyze

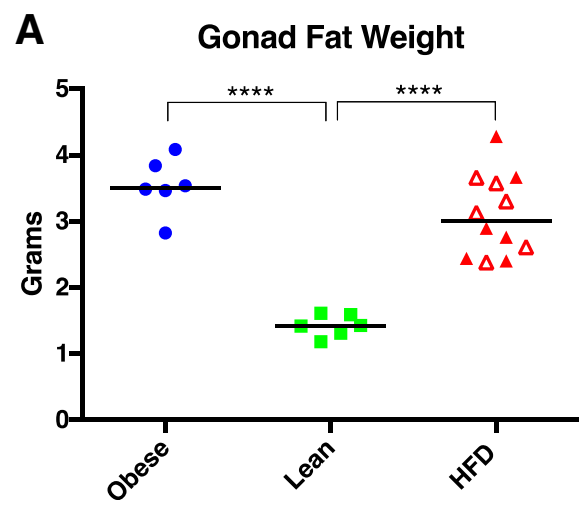

B

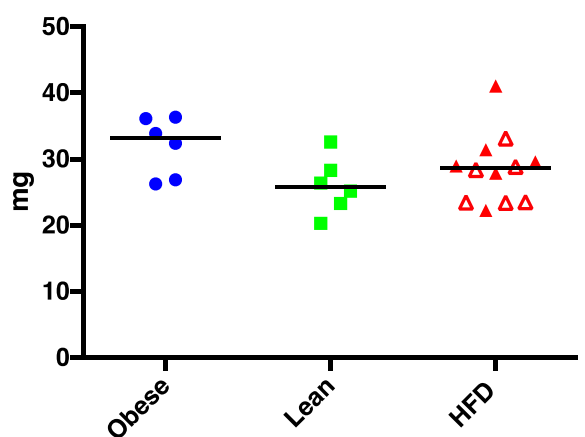

Fig. 2 Weight of gonad fat (a) and IFP (b) in obese, lean, and HFD groups. Black line represents mean value. Open red triangles designate animals receiving the restricted HFD; closed triangles define animals on the ad libitum HFD. ${ }^{* * *} P<0.0001$ 


\section{OA Scores}

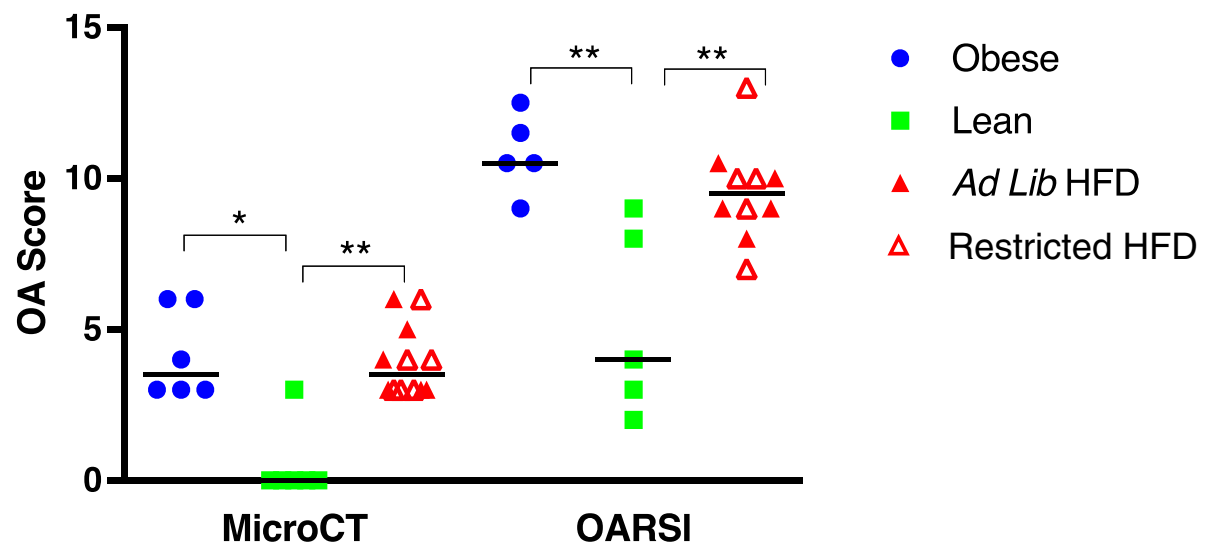

Fig. 3 MicroCT and OARSI histologic scores in obese, lean, and HFD groups. Black line represents mean value. ${ }^{*} P<0.05$, ${ }^{* *} P<0.01$

serum. Serum protein C3 levels were similar among the obese and HFD groups and were significantly higher than levels present in the lean group (Fig. 6b).

In addition to the higher platelet and protein C3 levels, two other significant differences were noted on serum biochemical profiles. Total cholesterol levels were higher in both the obese and HFD groups compared to lean animals (Fig. 6c). Interestingly, there was a wide spread of cholesterol values for the HFD group, with some animals having values similar to those of the lean group and others having much higher serum concentrations. In addition, blood urea nitrogen (BUN), a protein breakdown product excreted by the kidneys, was similar in the obese and lean groups. BUN in the HFD group was significantly lower than levels seen in both the obese and lean groups (Fig. 6d).

\section{Gene expression data from the IFP}

As the goal of this study was to determine how HFD and calorie restriction affect knee OA, we were particularly interested to see how these dietary manipulations
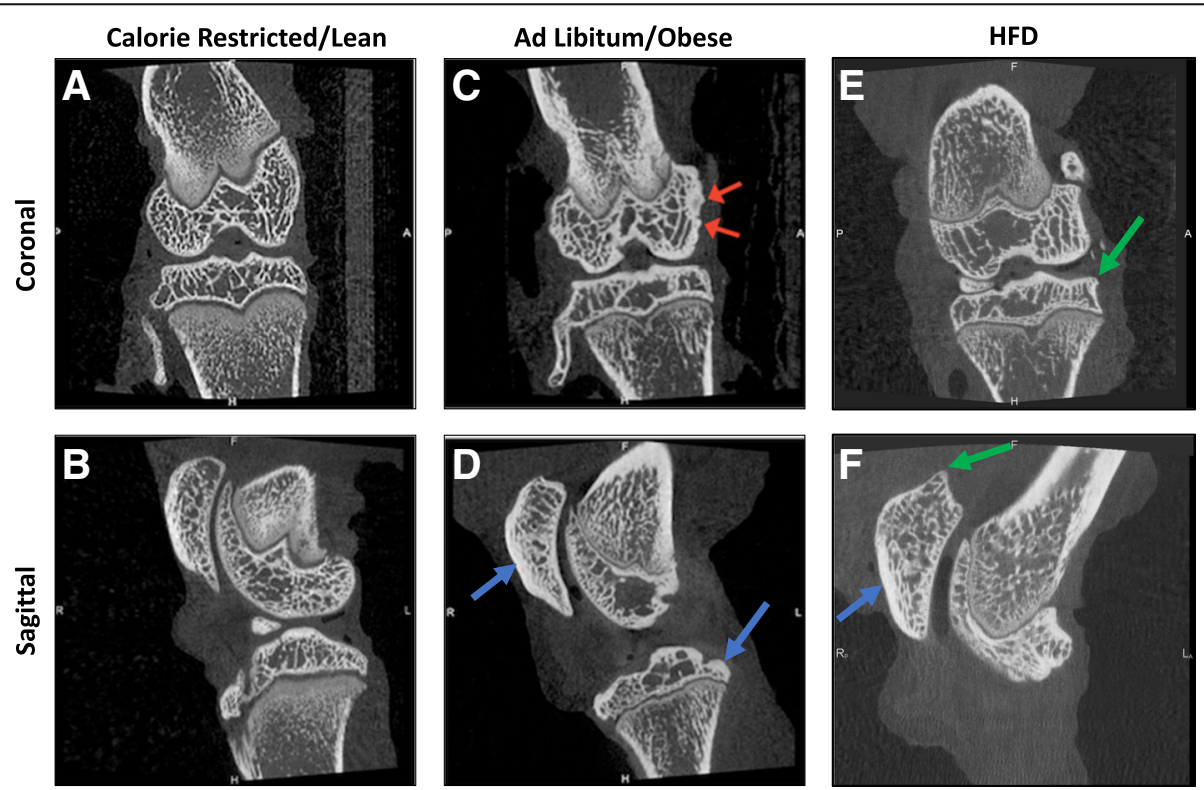

Fig. 4 a Dorsal and b sagittal reconstructions from a calorie-restricted animal with no OA lesions. MicroCT OA score of 0. c Dorsal reconstruction from an obese animal. There is sclerosis and small enthesiophytes on the medial femoral condyle (red arrows) and mild sclerosis of the central tibial plateau. d Sagittal reconstruction from same animal. Mild sclerosis of the cranial patella and caudal tibial condyle is present (blue arrows). MicroCT OA score of 6. e Dorsal reconstruction of an animal on the HFD. On the medial tibial condyle, there is a small osteophyte (green arrow). f HFD sagittal reconstruction. There is a small osteophyte on the proximal patella (green arrow), as well as mild sclerosis on the cranial patella (blue arrow). MicroCT OA score of 4 

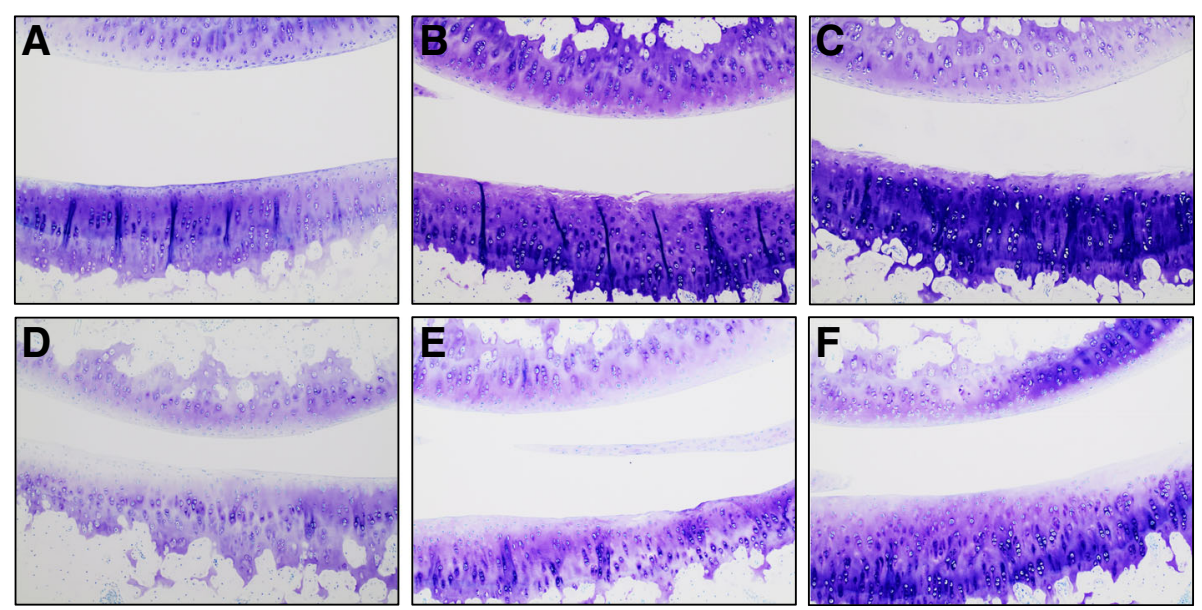

Fig. 5 a T blue photomicrograph of the medial compartment from a calorie-restricted animal. The articular surface is smooth with only mild superficial proteoglycan loss. b, c T blue photomicrographs from obese animals. The articular surfaces are fibrillated, there is proteoglycan loss in the superficial and middle zones, and there is cell clustering. $\mathbf{d}$-f $\mathbf{T}$ blue photomicrographs from HFD-fed animals. There is regional to diffuse proteoglycan loss in the superficial and middle zones, mild articular surface irregularity, occasional cell clustering, and focal cell loss within the superficial zone

might affect the IFP. Using NanoString technology, absolute mRNA counts for many pro- and anti-inflammatory cytokines, chemokines, and matrix metalloproteinase (MMP) genes were evaluated (Table 1). Numerous proinflammatory genes were upregulated in the HFD group. Compared to the lean group, the HFD animals had higher expression of several pro-inflammatory genes including IL-5, nuclear factor kappa beta (NFkB), cyclooxygenase 2 (COX2), transforming growth factor- $\beta$ (TGF- $\beta$ ), and TNF. Compared to the obese group, HFD-fed animals exhibited higher expression of IL-6, MCP-1, NFkB, COX2, and TNF. Additionally, the HFD group had higher expression
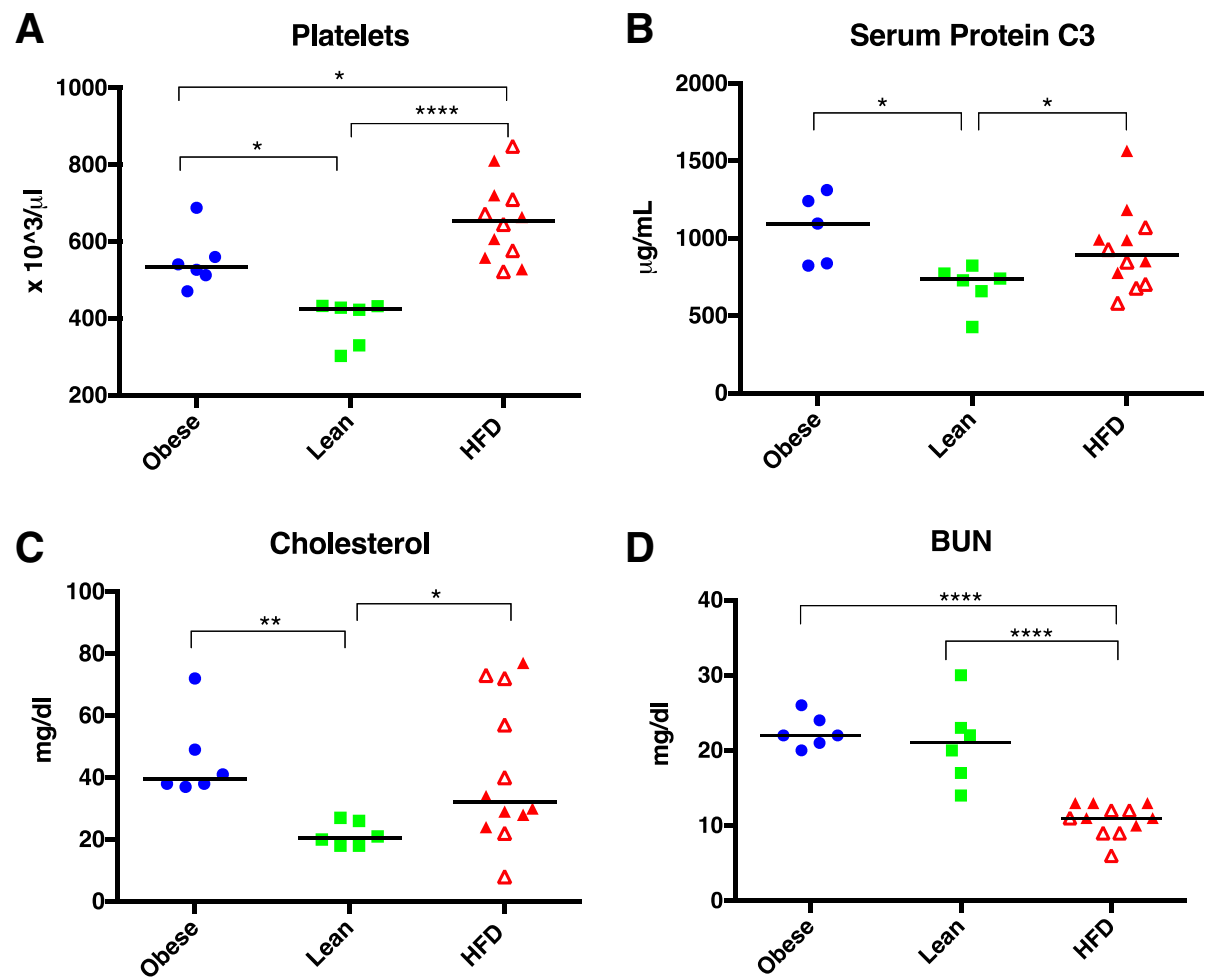

Fig. 6 Total platelet counts (a), protein C3 levels (b), serum cholesterol (c), and serum BUN (d) in obese, lean, and HFD groups. Black line represents mean values. Open red triangles designate animals receiving the restricted HFD; closed triangles define animals on the ad libitum HFD. ${ }^{*} P<0.05,{ }^{* *} P<0.01,{ }^{* * *} P<0.0001$ 
of matrix metalloproteinase-13 (MMP13), which cleaves type II collagen, than both the obese and lean groups. Expression of MMP2, which cleaves type IV collagen, and tissue inhibitor of metalloproteinases 2 (Timp2), an inhibitor of MMP activity, were also higher in the HFD group than the obese group.

When examining adipokines and other genes related to lipid metabolism, there were also several notable differences in gene expression among the groups. Leptin, an adipokine that normally inhibits hunger but exhibits resistance in obesity, was significantly increased in the HFD group compared to the lean group. It also trended towards being higher in the obese regular chow group compared to lean animals, but this did not reach statistical significance. Adiponectin, an adipokine that is traditionally decreased systemically in obesity, had higher gene expression in the IFP of the HFD group compared to the obese regular chow group. Lipoprotein lipase (LPL), which hydrolyzes triglycerides for cellular use, was increased in the lean regular chow group compared to both the obese regular chow and HFD groups. It was also higher in the HFD group compared to obese regular chow animals. Finally, peroxisome proliferatoractivator gamma (PPAR $\gamma$ ) was increased in the lean regular chow group compared to both the obese regular chow and HFD groups.

\section{Immunohistochemistry for MCP-1}

Little to no MCP-1 immunostaining was seen within chondrocytes in the lean group (Fig. 7), which was confirmed by significantly lower mean percentage of positive cells and mean integrated intensity (Fig. 8). In contrast, MCP-1 protein expression was prominent within chondrocytes in the obese regular chow group and the HFD group, which is consistent with the microCT and histologic assessment of OA provided above. Staining for MCP-1 within the extracellular matrix was minimal in all three groups.

\section{Discussion}

This study demonstrates that calorie-restriction using a low-fat, regular chow diet lessens OA severity early in disease onset in a guinea pig model of spontaneous disease.
An interesting, yet unintended, outcome of the study was that animals fed the HFD essentially self-imposed calorie restriction, despite being fed ad libitum. Due to their fastidious nature, guinea pigs in this group ate less food than expected, resulting in body weights that were similar to those seen in the purposefully calorie-restricted, regular chow group. Despite similar body weights among the HFD and calorie-restricted groups, microCT and histologic OA scores were worse in the HFD group. Thus, the benefits of calorie-restriction appear to be diminished by the proinflammatory nature of the HFD. Our findings lend support to the growing body of evidence that the link between OA and adiposity may be attributable to systemic and local knee joint inflammation. Total body weight ranged from 645 to $816 \mathrm{~g}$ in the HFD group. Interestingly, heavier animals in this group had worse microCT OA scores $(r=$ $0.62, P=0.0313)$. Thus, increased weight-bearing on joints cannot be excluded as a factor in the development of knee joint OA. Rather, it seems likely that both loading forces and inflammation contribute to disease development.

In the current study, obese regular chow-fed animals had similar OA scores as leaner animals fed a HFD. Despite the difference in total body weight, a major abdominal fat depot was similarly sized between these two groups. These findings suggest that the HFD animals, although lean, had reduced lean muscle mass. This was corroborated by the decreased size of the masseter muscle in the HFD group compared to the obese regular chow group. The lower BUN in the HFD animals is another indication of lower muscle mass, but may also be attributed to decreased protein consumption in this group. When comparing the macronutrient composition of the regular chow and highfat diets, the proportion of carbohydrates was similar; however, the HFD contained $30 \%$ fat and $18 \%$ protein, while the regular chow contained $12 \%$ fat and $31 \%$ protein. It is possible that either the lesser amount of protein and/or higher amount of fat content in the diet contributed to reduced muscle mass in the HFD group.

Regardless of body weight differences between the obese and HFD groups, they exhibited similar OA scores. This indicates that diet composition, and not simply body weight or calorie-restriction, alone, may play a key role in

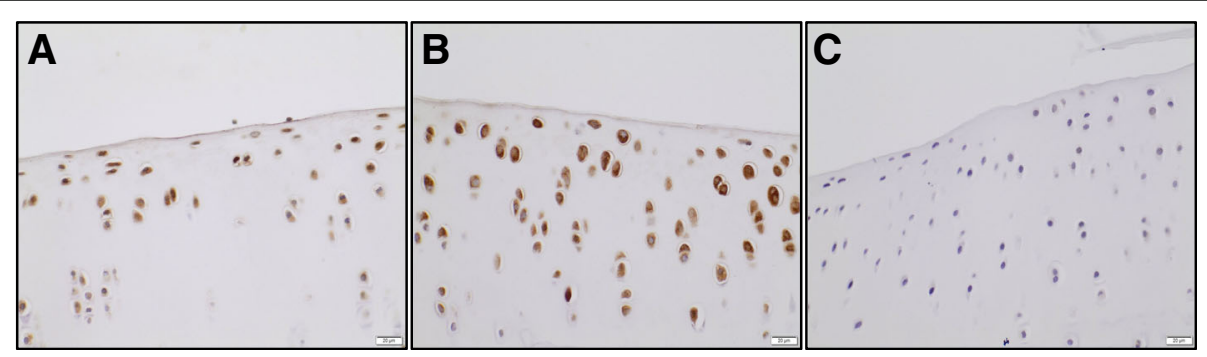

Fig. 7 Representative images of immunostaining for MCP-1 on the medial tibial plateau for the ad libitum regular chow group (a), the HFD group (b), and calorie-restricted group (c). $\times 400$ 
A

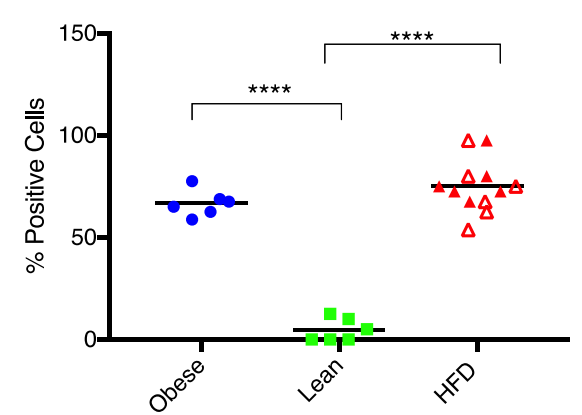

B

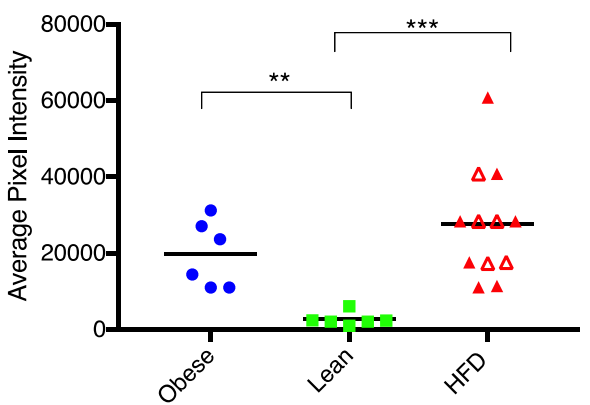

Fig. 8 The mean percentage of positive cells (a) and mean integrated intensity (b) of MCP-1 immunostaining in articular cartilage from both femoral condyles and tibial plateaus in obese, lean, and HFD groups. Black line represents mean values. Open red triangles designate animals receiving the restricted HFD; closed triangles define animals on the ad libitum HFD. ${ }^{*} P<0.01,{ }^{* * *} P<0.001,{ }^{* * *} P<0.0001$

the development of primary OA. The abdominal fat depot was significantly smaller in the calorie-restricted regular chow group. This finding suggests that animals fed the HFD maintained higher levels of adiposity, with smaller muscle mass, despite having body weights comparable to the calorie-restricted regular chow group.

In contrast to the variably sized abdominal fat depot among the three diet groups, the local knee joint adipose tissue, the IFP, was similarly sized among all three diet groups. Thus, it appears that the IFP is well-preserved, even in the face of calorie restriction. While more exploration is required to define the specific role of the IFP in OA, the current findings suggest preservation of this tissue depot may be essential to joint health. A few studies employing HFD-induced mouse models of OA found that IFP volume or area increased after being fed a HFD [21, 23, 49]. Human studies examining relationships between body mass index (BMI) and IFP size have yielded conflicting results. At least two studies have found no association between body mass index and IFP size in both lean and overweight/obese individuals [50, 51]. Results of the current study mimic what has been reported in these human studies, with no differences in IFP weight found despite differing total body weights in guinea pigs. However, other studies have shown positive correlations between IFP size and body weight in women $[52,53]$. More work is needed to further clarify the role of IFP in both healthy and obese individuals.

While overall mass of the IFP was similar among the three groups, gene expression profiles of the IFP differed. Previous studies have shown that IFPs removed from OA patients have increased gene expression of a multitude of cytokines $[54,55]$. Thus, we were interested to see how dietary factors may affect IFP gene expression in the guinea pig model. In general, expression of pro-inflammatory genes was higher in the HFD group compared to both obese and calorie-restricted regular chow groups. Specifically, NFkB, a transcription factor, and downstream targets IL-6 and TNF exhibited increased expression in the HFD group. It is wellestablished that both HFDs and obesity incite a chronic, low-grade inflammatory state due to upregulated NFkB and subsequent secretion of inflammatory cytokines such as IL-1, IL-6, and TNF [56, 57]. Here, we demonstrate that upregulation of these genes occurs locally in the knee joint in the IFP, potentially directly contributing to inflammation and subsequent $\mathrm{OA}$ in guinea pigs fed a HFD. Other pro-inflammatory pathways that were upregulated in the HFD group include the COX2 pathway, as well as the chemotactic factor MCP-1. Many of these pro-inflammatory cytokines and adipokines are known to increase activity of cartilage-degrading MMPs [58].

The current study also demonstrated increased gene expression of MMP13 in the HFD group compared to both the obese ad libitum and lean calorie-restricted groups. MMP13 primarily degrades type II collagen, a major constituent of the extracellular cartilage matrix. Additionally, MMP2 gene expression was higher in the HFD group compared to the obese ad libitum group. MMP2 cleaves type IV collagen. Type IV collagen is found in the pericellular matrix directly adjacent to chondrocytes and has anti-angiogenic properties that may play a role in maintaining an avascular and hypoxic environment in normal, healthy cartilage [59]. In damaged cartilage, the relative abundance of type IV collagen drops precipitously [60]. Our data suggest that MMP activity originating from the IFP in obese and HFD-fed animals may contribute to degradation of types II and IV collagen in cartilage. Interestingly, while total OA scores were similar between the obese and HFD groups, the features contributing to these scores differed. Thus, it may be worthwhile to determine whether this alteration in MMP activity may explain the differences in OA pathology seen in these treatment groups.

Given the abundance of gene expression data indicating increased inflammation within knee joints of the 
HFD and obese regular chow groups, IHC probing for MCP-1 protein expression was performed. Expression of this protein in chondrocytes were similar between the obese regular chow and HFD groups, while expression was not present in the lean calorie-restricted group. This is in interesting contrast to the Nanostring data that indicated higher MCP-1 levels in the IFP of HFD animals compared to obese animals. The reason for this discrepancy is uncertain but is likely related to posttranscriptional regulation of MCP-1 [61] or differential expression of this protein in different tissue types. Regardless, these findings confirm that there is increased inflammation within the knee joint in the obese and HFD groups compared to the lean group. Likewise, this data supports the premise that calorie-restriction with a low-fat diet results in low levels of knee joint inflammation. MCP-1 is a pro-inflammatory chemokine that plays a key role in $\mathrm{OA}$ pathogenesis and neuropathic pain [62]. Synovial fluid MCP-1 levels have been associated with radiographic knee $\mathrm{OA}$ and clinical symptoms in humans [63, 64]. Human articular chondrocytes express MCP-1, which increases expression of MMPs resulting in proteoglycan loss in vitro $[65,66]$. Additionally, administration of an MCP-1 signaling inhibitor protected cartilage after joint injury in a rat model [67].

In addition to evidence of local inflammation in the knee joint of the guinea pigs on the HFD, animals also had signs of increased systemic inflammation. While perhaps not at a level able to incite an increased white blood cell count on routine CBCs, the increased platelet count in both the HFD and obese regular chow groups compared to calorie-restricted regular chow animals may indicate a higher level of systemic inflammation. Cytokines, particularly IL-6, stimulate thrombopoiesis in the bone marrow [68], which results in a reactive thrombocytosis in a variety of inflammatory conditions, including obesity [69]. An increased platelet count, alone, however, is not specific for inflammation. Lack of differences in white blood cell numbers may be due to the low-grade or relatively short-term nature of the inflammatory response typically described with obesity. As such, we measured a more sensitive and specific biomarker of inflammation, serum protein C3, an acute phase reactant in guinea pigs [70]. This assay confirmed that both the HFD and obese regular chow groups had greater levels of circulating inflammatory proteins than $\mathrm{CR}$ regular chow animals. In humans, the major acute phase reactant, C-reactive protein, has been correlated to severity of radiographic OA [71]. Similar to these human studies, serum C3 levels were positively correlated to radiographic microCT OA score $(r=0.45, P=$ 0.0395) in the current study.

An intriguing finding of the current study was the variability in the types of cartilage lesions noted between the obese ad libitum group and the HFD group. Levels of systemic inflammation and overall OARSI OA scores for these two groups were similar; however, the types of lesions observed differed. In the obese ad libitum group, there were more fibrillations and fissures in the articular cartilage surface. In the HFD group, proteoglycan loss was more prominent. The reason for these differences should be pursued, although we speculate it may be due to locally driven changes and mechanical differences. Increased loading on joints in the obese group may more directly cause surface damage via formation of fissures. Loss of proteoglycan in the HFD group may be due to systemic inflammation or due to decreased protein content in the diet. The differences observed between the obese and HFD groups suggest local inflammation within the knee joint (including differences in IFP phenotype) are more influential to OA outcome than levels of systemic inflammation. Of note, types of lesions noted on microCT did not differ between these groups. More differences in bony changes may emerge if our analyses extended beyond 5 months of age.

Of note, the current study utilized only saturated fats in the HFD. This was necessitated in order to make a shelf-stable pellet at room temperature. However, it is well-established that saturated fats induce inflammation. Future investigations will alter fat composition of the diet to include unsaturated fats to determine if overall percentage of fat in the diet or fatty acid composition is more important in driving development of OA. It is also important to repeat this research using female animals to determine if there may be any sex differences in response to diet. Extending this study beyond 5 months of age is also needed to determine long-term effects of these diets. It would also be interesting to assess lameness via gait analysis or cage monitoring. Finally, directed mechanistic studies are necessary to identify specific pathways contributing to the pathology noted in this experiment. To the authors' knowledge, this is the first study to examine the IFP in the guinea pig. Our results suggest the IFP plays a role in disease development and that inflammatory profiles of the IFP are altered by changes in diet. More work is warranted to further define the role of the IFP in the development of spontaneous OA in this model.

\section{Conclusions}

This study provides several important conclusions regarding effects of diet on development of spontaneous OA. Firstly, calorie restriction was able to delay the onset of OA in disease-prone Hartley guinea pigs. Secondly, the benefit of calorie-restriction was diminished in animals eating a high-fat diet. This is likely due to the higher levels of systemic and local inflammation seen in these animals. Thus, diet composition, and not calorie 
content alone, must be considered a key player in development of OA. Additional studies are needed to determine if dietary composition influences OA outcomes in humans, but the current study indicates that high-fat diets may not be optimal for long-term knee joint health.

\section{Additional files}

Additional file 1: Table S1. Normalized absolute nCounter mRNA counts present in gonad fat. Data is represented as the mean (range). (DOCX $16 \mathrm{~kb}$ )

Additional file 2: Table S2. Normalized absolute nCounter mRNA counts present in gonad fat versus IFP in the three groups. Data is represented as the mean (range). (DOCX $16 \mathrm{~kb}$ )

\section{Abbreviations}

ANOVA: Analysis of variance; BMI: Body mass index; BUN: Blood urea nitrogen; CBC: Complete blood count; Cl: Confidence interval; COX2: Cyclooxygenase 2; CSU: Colorado State University; DNA: Deoxyribonucleic acid; EDTA: Ethylenediaminetetraacetic acid; ELISA: Enzyme-linked immunosorbent assay; HFD: High-fat diet; IFP: Infrapatellar fat pad; IHC: Immunohistochemistry; IL: Interleukin; LPL: Lipoprotein lipase; MCP-1: Monocyte chemoattractant protein 1; MicroCT: Microcomputed tomography; MMP: Matrix metalloproteinase; mRNA: Messenger RNA; NFkB: Nuclear factor kappa B; NIH: National Institutes of Health; OA: Osteoarthritis; OARSI: Osteoarthritis Research Society International; PBS: Phosphate-buffered saline; PPARY: Peroxisome proliferatoractivator gamma; RNA: Ribonucleic acid; T blue: Toluidine blue; TGF$\beta$ : Transforming growth factor beta; Timp2: Tissue inhibitor of matrix metalloproteinase 2; TNF: Tumor necrosis factor

\section{Acknowledgements}

Not applicable.

\section{Authors' contributions}

LBR carried out all benchtop assays, performed the data analysis, helped in the experimental design, and was a major contributor in writing the manuscript. AJM interpreted all microCT data. LC performed all IHC for MCP1. KSS was responsible for the conceptualization and design of the experiments, oversaw all the assays and analyses, and wrote the manuscript. All authors read and approved the final manuscript.

\section{Funding}

The majority of the work was funded through internal monies provided to KSS. This work was also supported in part by the Animal Imaging Shared Resource of the University of Colorado Cancer center (P30CA046934). Funding bodies had no role in the design, data analysis, or writing of the manuscript.

\section{Availability of data and materials}

The datasets used and analyzed during the current study are available from the corresponding author on reasonable request.

All data generated or analyzed during this study are included in this published article [and its supplementary information files].

\section{Ethics approva}

All animal procedures were approved by CSU IACUC.

\section{Consent for publication}

Not applicable.

\section{Competing interests}

The authors declare that they have no competing interests.

\section{Author details}

'Department of Microbiology, Immunology, Pathology, Colorado State University, 200 West Lake Street, Fort Collins, CO 80521, USA. ${ }^{2}$ Department of
Environmental and Radiological Health Sciences, Colorado State University, 123 Flint Cancer Center, Fort Collins, CO 80523, USA.

Received: 2 November 2018 Accepted: 23 May 2019

Published online: 13 June 2019

\section{References}

1. Cross M, Smith E, Hoy D, Nolte S, Ackerman I, Fransen M, et al. The global burden of hip and knee osteoarthritis: estimates from the global burden of disease 2010 study. Ann Rheum Dis. 2014;73(7):1323-1330. Available from: http://www.ncbi.nlm.nih.gov/pubmed/24553908.[cited 2016 Jul 19]

2. McCulloch K, Litherland GJ, Rai TS. Cellular senescence in osteoarthritis pathology. Aging Cell. 2017;16(2):210-8 Available from: http://www.ncbi. nlm.nih.gov/pubmed/28124466. [cited 2017 Jun 28].

3. Martel-Pelletier J, Barr AJ, Cicuttini FM, Conaghan PG, Cooper C, Goldring MB, et al. Osteoarthritis. Nat Rev Dis Prim. 2016;2:16072 Available from: http://www.ncbi.nlm.nih.gov/pubmed/27734845. [cited 2017 Jun 28].

4. Collaborators TG 2015 O. Health effects of overweight and obesity in 195 countries over 25 years. N Engl J Med. 2017;377(1):13-27 Available from: http://www.nejm.org/doi/10.1056/NEJMoa1614362. [cited 2017 Jun 28].

5. Pottie P, Presle N, Terlain B, Netter P, Mainard D, Berenbaum F. Obesity and osteoarthritis: more complex than predicted! Ann Rheum Dis. 2006;65(11): 1403-5 Available from: http://www.ncbi.nlm.nih.gov/pubmed/17038451. [cited 2017 Jun 28].

6. Carman WJ, Sowers M, Hawthorne VM, Weissfeld LA. Obesity as a risk factor for osteoarthritis of the hand and wrist: a prospective study. Am J Epidemiol. 1994;139(2):119-29 Available from: http://www.ncbi.nlm.nih.gov/ pubmed/8296779. [cited 2017 Jun 28].

7. Bliddal H, Leeds AR, Christensen R. Osteoarthritis, obesity and weight loss: evidence, hypotheses and horizons - a scoping review. Obes Rev. 2014; 15(7):578-86 Available from: http://www.ncbi.nlm.nih.gov/pubmed/ 24751192. [cited 2018 Aug 8].

8. Kulkarni K, Karssiens T, Kumar V, Pandit H, Murray CJ, Lopez AD, et al. Obesity and osteoarthritis. Maturitas. 2016;89:22-8 Available from: http:// www.ncbi.nlm.nih.gov/pubmed/27180156. [cited 2016 Aug 1].

9. Vuolteenaho K, Koskinen A, Moilanen E. Leptin - a link between obesity and osteoarthritis. applications for prevention and treatment. Basic Clin Pharmacol Toxicol. 2014;114(1):103-8 Available from: http://www.ncbi.nlm. nih.gov/pubmed/24138453. [cited 2018 Aug 8].

10. Berenbaum F, Eymard F, Houard X. Osteoarthritis, inflammation and obesity. Curr Opin Rheumatol. 2013;25(1):114-8 Available from: http://www.ncbi.nlm. nih.gov/pubmed/23090672. [cited 2018 Jul 18].

11. Cancello R, Clément K. Review article: is obesity an inflammatory illness? Role of low-grade inflammation and macrophage infiltration in human white adipose tissue. BJOG An Int J Obstet Gynaecol. 2006;113(10):1141-7 Available from: http://www.ncbi.nlm.nih.gov/pubmed/16903845. [cited 2018 Aug 8].

12. Herder C, Schneitler S, Rathmann W, Haastert B, Schneitler H, Winkler H, et al. Low-grade inflammation, obesity, and insulin resistance in adolescents. J Clin Endocrinol Metab. 2007;92(12):4569-74 Available from: https:// academic.oup.com/jcem/article-lookup/doi/10.1210/jc.2007-0955. [cited 2018 Aug 8].

13. Monteiro R, Azevedo I. Chronic inflammation in obesity and the metabolic syndrome. Mediators Inflamm. 2010;2010 Available from: http://www.ncbi. nlm.nih.gov/pubmed/20706689. [cited 2018 Aug 8].

14. Magnuson A, Fouts J, Booth A, Foster M. Obesity-induced chronic low grade inflammation: gastrointestinal and adipose tissue crosstalk. Integr Obes Diabetes. 2015;1(5) Available from: http://oatext.com/Obesity-inducedchronic-low-grade-inflammation-Gastrointestinal-and-adipose-tissuecrosstalk.php. [cited 2018 Aug 8].

15. Sartori-Cintra AR, Aikawa P, Cintra DE. Obesity versus osteoarthritis: beyond the mechanical overload. Einstein (Sao Paulo). 2014;12(3):374-9 Available from: http://www.ncbi.nlm.nih.gov/pubmed/25184806. [cited 2017 Jun 28].

16. Collins KH, Paul HA, Reimer RA, Seerattan RA, Hart DA, Herzog W. Relationship between inflammation, the gut microbiota, and metabolic osteoarthritis development: studies in a rat model. Osteoarthr Cartil. 2015; 23(11):1989-98 Available from: http://linkinghub.elsevier.com/retrieve/pii/ S1063458415008559. [cited 2017 Jun 28].

17. Pou KM, Massaro JM, Hoffmann U, Vasan RS, Maurovich-Horvat P, Larson MG, et al. Visceral and subcutaneous adipose tissue volumes are crosssectionally related to markers of inflammation and oxidative stress. 
Circulation. 2007;116(11) Available from: http://circ.ahajournals.org/content/ 116/11/1234. [cited 2017 Jul 18].

18. Fernandes JC, Martel-Pelletier J, Pelletier J-P. The role of cytokines in osteoarthritis pathophysiology. Biorheology. 2002;39(1-2):237-46 Available from: http://www.ncbi.nlm.nih.gov/pubmed/12082286. [cited 2017 Jul 18].

19. Wu C-L, Jain D, McNeill JN, Little D, Anderson JA, Huebner JL, et al. Dietary fatty acid content regulates wound repair and the pathogenesis of osteoarthritis following joint injury. Ann Rheum Dis. 2015;74(11):2076-83 Available from: http://ard.bmj.com/lookup/doi/10.1136/annrheumdis-2014205601. [cited 2017 Jul 18].

20. Mooney RA, Sampson ER, Lerea J, Rosier RN, Zuscik MJ. High-fat diet accelerates progression of osteoarthritis after meniscal/ligamentous injury. Arthritis Res Ther. 2011;13(6):R198 Available from: http://arthritis-research. biomedcentral.com/articles/10.1186/ar3529. [cited 2017 Jul 18].

21. Chang W, Demoe J, Kent C, Kovats S, Garteiser P, Doblas S, et al. Infrapatellar fat pad hypertrophy without inflammation in a diet-induced mouse model of obesity and osteoarthritis. Osteoarthr Cartil. 2011;19(1):S66 Available from: http://www.oarsijournal.com/article/S1063-4584(11)60157-X/ pdf. [cited 2017 Oct 25].

22. Griffin TM, Fermor B, Huebner JL, Kraus VB, Rodriguiz RM, Wetsel WC, et al. Diet-induced obesity differentially regulates behavioral, biomechanical, and molecular risk factors for osteoarthritis in mice. Arthritis Res Ther. 2010;12(4): R130 Available from: http://arthritis-research.biomedcentral.com/articles/10. 1186/ar3068. [cited 2017 Jul 18].

23. Iwata $\mathrm{M}$, Ochi $\mathrm{H}$, Hara $\mathrm{Y}$, Tagawa M, Koga D, Okawa A, et al. Initial responses of articular tissues in a murine high-fat diet-induced osteoarthritis model: pivotal role of the IPFP as a cytokine fountain. Fritz JH, editor. PLoS One. 2013;8(4):e60706 Available from: http://dx.plos.org/10.1371/journal.pone. 0060706. [cited 2018 Jun 27].

24. Collins KH, Hart DA, Seerattan RA, Reimer RA, Herzog W. High-fat/highsucrose diet-induced obesity results in joint-specific development of osteoarthritis-like degeneration in a rat model. Bone Joint Res. 2018;7(4): 274-81 Available from: http://www.ncbi.nlm.nih.gov/pubmed/29922445. [cited 2018 Aug 10].

25. Brunner AM, Henn CM, Drewniak El, Lesieur-Brooks A, Machan J, Crisco JJ, et al. High dietary fat and the development of osteoarthritis in a rabbit model. Osteoarthr Cartil. 2012;20(6):584-92 Available from: http://linkinghub.elsevier. com/retrieve/pii/S1063458412000714. [cited 2017 Jul 18].

26. Cordain L, Eaton SB, Sebastian A, Mann N, Lindeberg S, Watkins BA, et al. Origins and evolution of the Western diet: health implications for the $21 \mathrm{st}$ century. Am J Clin Nutr. 2005;81 (2):341-54 Available from: http://www.ncbi. nlm.nih.gov/pubmed/15699220. [cited 2017 Jul 18].

27. McNeill JN, Wu C-L, Rabey KN, Schmitt D, Guilak F. Life-long caloric restriction does not alter the severity of age-related osteoarthritis. Age (Omaha). 2014;36(4):9669 Available from: http://www.ncbi.nlm.nih.gov/ pubmed/24981112. [cited 2017 may 30].

28. Fontana L, Klein S. Aging, adiposity, and calorie restriction. JAMA. 2007: 297(9):986 Available from: http://www.ncbi.nlm.nih.gov/pubmed/17341713. [cited 2017 Jul 25]

29. Paolisso G, Rizzo MR, Mazziotti G, Tagliamonte MR, Gambardella A, Rotondi $M$, et al. Advancing age and insulin resistance: role of plasma tumor necrosis factor-alpha. Am J Physiol. 1998;275(2 Pt 1):E294-9 Available from: http://www.ncbi.nlm.nih.gov/pubmed/9688632. [cited 2017 Jul 25].

30. Weiss EP, Fontana L. Caloric restriction: powerful protection for the aging heart and vasculature. AJP Hear Circ Physiol. 2011;301(4):H1205-19 Available from: http://ajpheart.physiology.org/cgi/doi/10.1152/ajpheart.00685.2011. [cited 2017 Jul 25].

31. You T, Sonntag WE, Leng X, Carter CS. Lifelong caloric restriction and interleukin6 secretion from adipose tissue: effects on physical performance decline in aged rats. J Gerontol A Biol Sci Med Sci. 2007;62(10):1082-7 Available from: http:// www.ncbi.nlm.nih.gov/pubmed/17921419. [cited 2017 Jul 25].

32. Kealy RD, Lawler DF, Ballam JM, Lust G, Biery DN, Smith GK, et al. Evaluation of the effect of limited food consumption on radiographic evidence of osteoarthritis in dogs. J Am Vet Med Assoc. 2000;217(11):1678-80 Available from: http://www.ncbi.nlm.nih.gov/pubmed/11110459. [cited 2017 Jul 25].

33. Runge JJ, Biery DN, Lawler DF, Gregor TP, Evans RH, Kealy RD, et al. The effects of lifetime food restriction on the development of osteoarthritis in the canine shoulder. Vet Surg. 2008;37(1):102-7 Available from: http://doi. wiley.com/10.1111/j.1532-950X.2007.00354.x. [cited 2017 Jul 25].

34. Bendele AM, Hulman JF. Effects of body weight restriction on the development and progression of spontaneous osteoarthritis in guinea pigs.
Arthritis Rheum. 1991;34(9):1180-4 Available from: http://www.ncbi.nIm.nih. gov/pubmed/1930336. [cited 2017 Jul 25].

35. Kraus VB, Huebner JL, DeGroot J, Bendele A. The OARSI histopathology initiative - recommendations for histological assessments of osteoarthritis in the guinea pig. Osteoarthritis Cartilage. 2010;18(Suppl 3):S35-52 Available from: http://www.ncbi.nlm.nih.gov/pubmed/20864022. [cited 2016 Jul 19].

36. Jimenez PA, Glasson SS, Trubetskoy OV, Haimes HB. Spontaneous osteoarthritis in Dunkin Hartley guinea pigs: histologic, radiologic, and biochemical changes. Lab Anim Sci. 1997;47(6):598-601 Available from: http://www.ncbi.nlm.nih.gov/pubmed/9433695. [cited 2017 Jul 18].

37. Podell BK, Ackart DF, Richardson MA, DiLisio JE, Pulford B, Basaraba RJ. A model of type 2 diabetes in the guinea pig using sequential diet-induced glucose intolerance and streptozotocin treatment. Dis Model Mech. 2017; 10(2) Available from: http://dmm.biologists.org/content/10/2/151.long\#sec-1. [cited 2017 Jul 19].

38. West KL, Fernandez ML. Guinea pigs as models to study the hypocholesterolemic effects of drugs. Cardiovasc Drug Rev. 2004;22(1):5570 Available from: http://www.ncbi.nlm.nih.gov/pubmed/14978518. [cited 2017 Jul 25].

39. Madsen CS, Janovitz E, Zhang R, Nguyen-Tran V, Ryan CS, Yin X, et al. The guinea pig as a preclinical model for demonstrating the efficacy and safety of statins. J Pharmacol Exp Ther. 2008;324(2) Available from: http://jpet. aspetjournals.org/content/324/2/576?ijkey=

4b019e0e2f805e5b09e90609823822eb0d212453\&keytype2=tf_ipsecsha. [cited 2017 Jul 25].

40. Ensign WY, McNamara DJ, Fernandez ML. Exercise improves plasma lipid profiles and modifies lipoprotein composition in guinea pigs. J Nutr Biochem. 2002;13(12):747-53 Available from: http://www.ncbi.nlm.nih.gov/ pubmed/12550059. [cited 2017 Jul 25].

41. Fernandez ML, Wilson TA, Conde K, Vergara-Jimenez M, Nicolosi RJ. Hamsters and guinea pigs differ in their plasma lipoprotein cholesterol distribution when fed diets varying in animal protein, soluble fiber, or cholesterol content. J Nutr. 1999;129(7):1323-32 Available from: http://jn.nutrition.org/content/129/7/ 1323?ijkey=78e9dd394323a8562f3f2dfa2c6f849c9f56aae0\&keytype2=tf_ ipsecsha. [cited 2017 Jul 25].

42. Ye $\mathrm{P}$, Cheah IK, Halliwell B. High fat diets and pathology in the guinea pig. Atherosclerosis or liver damage? Biochim Biophys Acta - Mol Basis Dis. 2013; 1832(2):355-64 Available from: http://linkinghub.elsevier.com/retrieve/pii/ S0925443912002591. [cited 2017 Jul 25].

43. Tveden-Nyborg P, Birck MM, Ipsen DH, Thiessen T, de Feldmann LB, Lindblad MM, et al. Diet-induced dyslipidemia leads to nonalcoholic fatty liver disease and oxidative stress in guinea pigs. Transl Res. 2016;168:146-60 Available from: http:/www.ncbi.nlm.nih.gov/pubmed/26518991. [cited 2017 Jul 25].

44. Bendele AM, White SL, Hulman JF. Osteoarthrosis in guinea pigs: histopathologic and scanning electron microscopic features. Lab Anim Sci. 1989;39(2):115-21 Available from: http://www.ncbi.nlm.nih.gov/pubmed/ 2709799. [cited 2018 Jun 22].

45. Radakovich LB, Marolf AJ, Shannon JP, Pannone SC, Sherk VD, Santangelo KS. Development of a microcomputed tomography scoring system to characterize disease progression in the Hartley guinea pig model of spontaneous osteoarthritis. Connect Tissue Res. 2017:1-11 Available from: http://www.ncbi.nlm.nih.gov/pubmed/29226725. [cited 2018 Jun 20].

46. Idleburg C, DeLassus EN, Novack D V. Immunohistochemistry of skeletal tissues. In: Methods in molecular biology (Clifton, NJ). 2015. p. 87-95. Available from: http://www.ncbi.nlm.nih.gov/pubmed/25331045. [cited 2018 Jul 17]

47. Leven RM, Clark B, Tablin F. Effect of recombinant interleukin-6 and thrombopoietin on isolated guinea pig bone marrow megakaryocyte protein phosphorylation and proplatelet formation. Blood Cells Mol Dis. 1997;23(2):252-68 Available from: http://www.ncbi.nlm.nih.gov/pubmed/ 9410469. [cited 2018 Aug 8].

48. Rose SR, Petersen NJ, Gardner TJ, Hamill RJ, Trautner BW. Etiology of thrombocytosis in a general medicine population: analysis of 801 cases with emphasis on infectious causes. J Clin Med Res. 2012;4(6): 415-23 Available from: http://www.ncbi.nlm.nih.gov/pubmed/23226175. [cited 2018 Jun 21].

49. Barboza E, Hudson J, Chang WP, Kovats S, Towner RA, Silasi-Mansat R, Lupu F, Kent C, Griffin TM. Profibrotic Infrapatellar Fat Pad Remodeling Without M1 Macrophage Polarization Precedes Knee Osteoarthritis in Mice With Diet-Induced Obesity. Arthritis Rheumatol. 2017 Jun;69(6):1221-1232.

50. Chuckpaiwong B, Charles HC, Kraus VB, Guilak F, Nunley JA. Age-associated increases in the size of the infrapatellar fat pad in knee osteoarthritis as 
measured by 3T MRI. J Orthop Res. 2010;28(9):1149-54 Available from: http://doi.wiley.com/10.1002/jor.21125. [cited 2017 Oct 25].

51. Han W, Cai S, Liu Z, Jin X, Wang X, Antony B, et al. Infrapatellar fat pad in the knee: is local fat good or bad for knee osteoarthritis? Arthritis Res Ther 2014;16(4):R145 Available from: http://arthritis-research.biomedcentral.com/ articles/10.1186/ar4607. [cited 2017 Oct 25].

52. Diepold J, Ruhdorfer A, Dannhauer T, Wirth W, Steidle E, Eckstein F. Sexdifferences of the healthy infra-patellar ( $\mathrm{Hoffa}$ ) fat pad in relation to intermuscular and subcutaneous fat content--data from the steoarthritis Initiative. Ann Anat. 2015;200:30-6 Available from: http://linkinghub.elsevier. com/retrieve/pii/S0940960215000060. [cited 2017 Oct 26]

53. Ballegaard C, Riis RGC, Bliddal H, Christensen R, Henriksen M, Bartels EM, et al. Knee pain and inflammation in the infrapatellar fat pad estimated by conventional and dynamic contrast-enhanced magnetic resonance imaging in obese patients with osteoarthritis: a cross-sectional study. Osteoarthr Cartil. 2014;22(7):933-40 Available from: http://linkinghub.elsevier.com/ retrieve/pii/S1063458414010565. [cited 2017 Oct 26].

54. Clockaerts S, Bastiaansen-Jenniskens YM, Feijt C, De Clerck L, Verhaar JAN, Zuurmond A-M, et al. Cytokine production by infrapatellar fat pad can be stimulated by interleukin $1 \beta$ and inhibited by peroxisome proliferator activated receptor a agonist. Ann Rheum Dis. 2012:71(6):1012-8 Available from: http://www.ncbi.nlm.nih.gov/pubmed/22307941. [cited 2019 Feb 5].

55. Clockaerts S, Bastiaansen-Jenniskens YM, Runhaar J, Van Osch GJVM, Van Offel JF, Verhaar JAN, et al. The infrapatellar fat pad should be considered as an active osteoarthritic joint tissue: a narrative review. Osteoarthr Cartil. 2010;18(7):876-82 Available from: http://linkinghub.elsevier.com/retrieve/pii/ S1063458410001147. [cited 2018 Jun 27].

56. Cortez M, Carmo LS, Rogero MM, Borelli P, Fock RA. A high-fat diet increases $\|\mathrm{L}-1,\| \mathrm{L}-6$, and TNF-a production by increasing NF-KB and attenuating PPAR$\gamma$ expression in bone marrow mesenchymal stem cells. Inflammation. 2013: 36(2):379-86 Available from: http://www.ncbi.nlm.nih.gov/pubmed/ 23079940. [cited 2017 Oct 23].

57. Santangelo KS, Radakovich LB, Fouts J, Foster MT. Pathophysiology of obesity on knee joint homeostasis: contributions of the infrapatellar fat pad. Horm Mol Biol Clin Investig. 2016;26(2):97-108 Available from: https://www. ncbi.nlm.nih.gov/pubmed/9125256. [cited 2017 Oct 23]

58. Goldring MB, Otero M. Inflammation in osteoarthritis. Curr Opin Rheumatol. 2011;23(5):471-8 Available from: http://www.ncbi.nlm.nih.gov/pubmed/ 21788902. [cited 2018 Aug 22].

59. Foldager CB, Toh WS, Gomoll AH, Olsen BR, Spector M. Distribution of basement membrane molecules, laminin and collagen type IV, in normal and degenerated cartilage tissues. Cartilage. 2014;5(2):123-32 Available from: http://www.ncbi.nlm.nih.gov/pubmed/26069692. [cited 2018 Jun 21]

60. Foldager CB, Toh WS, Christensen BB, Lind M, Gomoll AH, Spector M. Collagen type IV and laminin expressions during cartilage repair and in late clinically failed repair tissues from human subjects. Cartilage. 2016;7(1):52-61 Available from: http://www.ncbi.nlm.nih.gov/pubmed/26958317. [cited 2018 Jun 21].

61. Panganiban RP, Vonakis BM, Ishmael FT, Stellato C. Coordinated posttranscriptional regulation of the chemokine system: messages from CCL2. J Interferon Cytokine Res. 2014;34(4):255-66 Available from: http://www.ncbi. nlm.nih.gov/pubmed/24697203. [cited 2019 Feb 5].

62. Scanzello CR. Chemokines and inflammation in osteoarthritis: insights from patients and animal models. J Orthop Res. 2017;35(4):735-9 Available from: http://www.ncbi.nlm.nih.gov/pubmed/27808445. [cited 2018 Jul 18].

63. Monibi F, Roller BL, Stoker A, Garner B, Bal S, Cook JL. Identification of synovial fluid biomarkers for knee osteoarthritis and correlation with radiographic assessment. J Knee Surg. 2016;29(3):242-7 Available from: http://www.thieme-connect.de/DOI/DOI?10.1055/s-0035-1549022. [cited 2018 Jul 25].

64. Ramesh G. Novel therapeutic targets in neuroinflammation and neuropathic pain. Inflamm Cell Signal. 2014;1(3) Available from: http://www.ncbi.nlm.nih. gov/pubmed/26052540. [cited 2018 Jul 25].

65. Borzi RM, Mazzetti I, Cattini L, Uguccioni M, Baggiolini M, Facchini A. Human chondrocytes express functional chemokine receptors and release matrixdegrading enzymes in response to $\mathrm{C}-\mathrm{X}-\mathrm{C}$ and $\mathrm{C}-\mathrm{C}$ chemokines. Arthritis Rheum. 2000:43(8):1734-41 Available from: http://doi.wiley.com/10.1002/ 1529-0131\%28200008\%2943\%3A8\%3C1734\%3A\%3AAID-ANR9\%3E3.0. CO\%3B2-B. [cited 2018 Jul 25].

66. Yuan GH, Masuko-Hongo K, Sakata M, Tsuruha J, Onuma H, Nakamura H, et al. The role of $\mathrm{C}-\mathrm{C}$ chemokines and their receptors in osteoarthritis. Arthritis Rheum. 2001:44(5):1056-70 Available from: http://doi.wiley.com/10.1002/
1529-0131\%28200105\%2944\%3A5\%3C1056\%3A\%3AAID-ANR186\%3E3.0. CO\%3B2-U. [cited 2018 Jul 25].

67. Appleton CTG, Usmani SE, Pest MA, Pitelka V, Mort JS, Beier F. Reduction in disease progression by inhibition of transforming growth factor a-CCL2 signaling in experimental posttraumatic osteoarthritis. Arthritis Rheumatol (Hoboken, NJ). 2015;67(10):2691-701 Available from: http://doi.wiley.com/10. 1002/art.39255. [cited 2018 Jul 25].

68. Yang M, Li K. The role of cytokines and transcription factors in megakaryocytopoiesis. Zhongguo shi yan xue ye xue za zhi. 2002;10(6):5805 Available from: http://www.ncbi.nlm.nih.gov/pubmed/12513728. [cited 2018 Jun 21]

69. Samocha-Bonet D, Justo D, Rogowski O, Saar N, Abu-Abeid S, Shenkerman $\mathrm{G}$, et al. Platelet counts and platelet activation markers in obese subjects. Mediators Inflamm. 2008;2008:834153 Available from: http://www.ncbi.nlm. nih.gov/pubmed/18385810. [cited 2018 Jun 21].

70. Sjunnesson H, Sturegard E, Grubb A, Willen R, Wadstrom T. Comparative study of Helicobacter pylori infection in guinea pigs and mice -- elevation of acute-phase protein C3 in infected guinea pigs. FEMS Immunol Med Microbiol. 2001;30(2):167-72 Available from: https://academic.oup.com/ femspd/article-lookup/doi/10.1111/j.1574-695X.2001.tb01566.x. [cited 2018 Jun 21].

71. Spector TD, Hart DJ, Nandra D, Doyle DV, Mackillop N, Gallimore JR, Pepys MB. Low-level increases in serum C-reactive protein are present in early osteoarthritis of the knee and predict progressive disease. Arthritis Rheum. 1997 Apr;40(4):723-7.

\section{Publisher's Note}

Springer Nature remains neutral with regard to jurisdictional claims in published maps and institutional affiliations.
Ready to submit your research? Choose BMC and benefit from:

- fast, convenient online submission

- thorough peer review by experienced researchers in your field

- rapid publication on acceptance

- support for research data, including large and complex data types

- gold Open Access which fosters wider collaboration and increased citations

- maximum visibility for your research: over $100 \mathrm{M}$ website views per year

At $\mathrm{BMC}$, research is always in progress.

Learn more biomedcentral.com/submissions 